\title{
Geomagnetic paleointensity over 1.2 Ma from deep-tow vector magnetic data across the East Pacific Rise
}

\author{
Michiko Yamamoto ${ }^{1}$, Nobukazu Seama ${ }^{2}$, and Nobuhiro Isezaki ${ }^{3}$ \\ ${ }^{1}$ Earth and Atmospheric Sciences, Cornell University, Snee Hall, Ithaca, NY 14853, U.S.A. \\ ${ }^{2}$ Research Center for Inland Seas, Kobe University, 1-1 Rokkodai, Nada, Kobe 657-8501, Japan \\ ${ }^{3}$ Department of Earth Science, Chiba University, 1-33 Yayoi, Inage, Chiba 263-8522, Japan
}

(Received November 8, 2004; Revised March 31, 2005; Accepted April 6, 2005)

\begin{abstract}
Deep-tow vector magnetic data have been acquired across the fast-spreading southern East Pacific Rise $18^{\circ} \mathrm{S}$ and inverted to magnetization intensity variations. Vector magnetic data are used to determine continuous magnetic intensity within intervals of constant polarity over the Matuyama and Brunhes periods up to the Cobb Mountain event at 1.19 Ma. A comparison of our deep-tow vector data and a sediment core-derived geomagnetic paleointensity timescale suggests that the short-wavelength magnetic anomaly signal is indeed of geomagnetic origin and can be used to date the seafloor with a high resolution. The crustal age determined from our date reveals a highly asymmetric spreading rate for the recent period (since $0.3 \mathrm{Ma}$ ).
\end{abstract}

Key words: Paleointensity variation, vector magnetic anomaly data, deep-tow survey, East Pacific Rise.

\section{Introduction}

Geomagnetic polarity reversals generate parallel magnetic lineations in the oceanic crust, which has been utilized for answering various questions about the science of the Earth. Sea-surface magnetic surveys now cover most of the world's ocean basin and are used, together with the geomagnetic polarity timescale, as a means to characterize the age and spreading geometry of the oceanic crust. Such studies have proven essential for our current understanding of plate motion and tectonic evolution of the mid-ocean ridge system. Despite this progress, we still have a limited resolution within polarity chrons, which may extend over a long period of time. To study details within a single polarity chron, we need to obtain high-resolution magnetic anomaly data and to establish global coherency. Geomagnetic paleointensity variations compiled from marine sediments have become a candidate for constructing a magnetic timescale within a polarity. Paleointensity variations published in the 1990s (Meynadier et al., 1992; Valet and Meynadier, 1993; Guyodo and Valet, 1996, 1999; Valet et al., 1999; Yamazaki, 1999) show great advances in better age control and in accuracy as the number of records increases. This also leads to a better continuity in time coverage, good enough to compare with the high-resolution magnetic anomaly data across or near the ocean ridge axis.

On the other hand, the resolution of some marine geomagnetic anomaly data is also improving as a result of advanced instruments for near-bottom surveys (e.g. Hussenoeder et al., 1996; Fujiwara and Fujimoto, 1998) and developed analysis methods to obtain and preserve the short wavelength feature that is an inherent difficulty in remote

Copy right(c) The Society of Geomagnetism and Earth, Planetary and Space Sciences (SGEPSS); The Seismological Society of Japan; The Volcanological Society of Japan; The Geodetic Society of Japan; The Japanese Society for Planetary Sciences; TERRAPUB surveys (Hussenoeder et al., 1995; Yamamoto and Seama, 2004). The short wavelength signals in a geomagnetic anomaly are often referred to as "tiny wiggles", and they have been recognized in many regions, even in sea surface data. However, the origin of these "tiny wiggles" is still controversial. They have been variously attributed to seafloor topography, various rock characteristics, presence of hydrothermal activity, variation of the magnetic layer thickness, and fluctuation of the geomagnetic field (Rea and Blakely, 1975; Tivey and Johnson, 1987, 1993; Cande and Kent, 1992; Wooldridge et al., 1992). Paleointensity variations seem to provide the most convincing explanation based on previous studies that report a good correlation between the observed high resolution magnetic anomalies and the variation of paleomagnetic intensity, as depicted from the independent sediment core record (Gee et al., 2000; Pouliquen et al., 2001; Bowers et al., 2001; Bowles et al., 2003).

This study is based on deep-tow vector magnetic data collected by a Deep-tow Three-Component Magnetometer (DTCM) instrument over the East Pacific Rise around $18^{\circ} \mathrm{S}$. We adopt a 2.5 -dimensional structure model to invert the magnetic anomaly to magnetization. Then we demonstrate good correlation between the magnetization and the sediment-derived paleointensity timescale, which indicates that paleointensity variations have a major effect on the tiny wiggles of a magnetic anomaly. Such data and analysis provide a basis for developing a high-resolution magnetic timescale within intervals of constant polarity.

(Nomenclature and ages of geomagnetic excursions in this paper are based on Valet and Meynadier (1993).)

\section{Data}

A DTCM developed to measure the magnetic vector field near the seafloor was first used for a geomagnetic inves- 


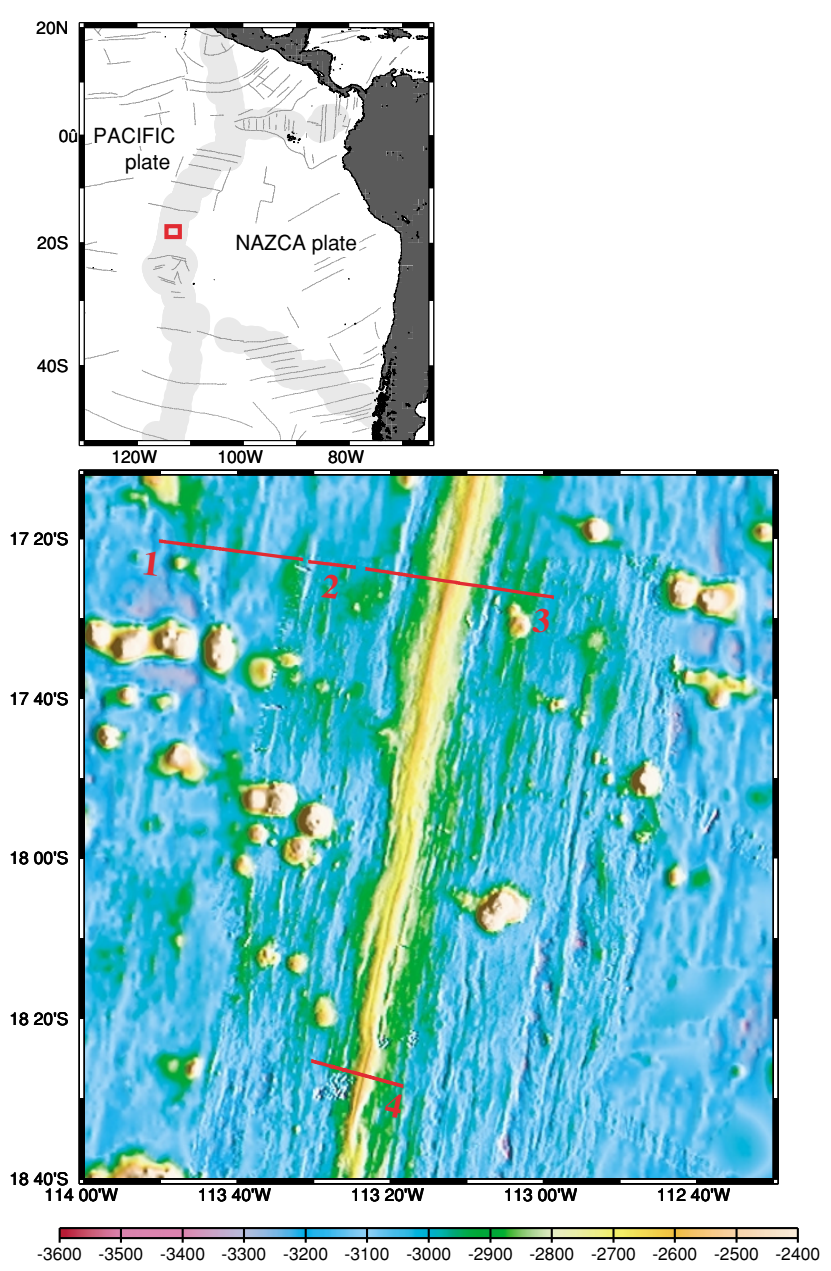

Fig. 1. Regional map showing the location of the study area on the East Pacific Rise (inset). Color contoured shaded relief plot of the bathymetry obtained from [TAMU]2 side-scan sonar data and Deep-Tow survey lines and track numbers.

tigation on the East Pacific Rise (EPR) around $18^{\circ} \mathrm{S}$ on board R/V ATLANTIS in September 1998. The DTCM is composed of triaxial fluxgate magnetometers and an attitude calibration unit mounted with three ring laser gyros and three single axis accelerometers. The position of the DTCM is known through the navigation data from a GPS on board and the local geometry information from the short base line acoustic measurement and pressure data. This survey area is characterized by an ultrafast spreading rate and high magmatic activity inferred by previous studies (Detrick et al., 1993; Scheirer and Macdonald, 1993; Mutter et al., 1995; Urabe et al., 1995; Auzende et al., 1996; Scheirer et al., 1998). Our data were collected along two survey lines across the EPR at an altitude of about $200 \mathrm{~m}$ above the sea floor. The first line crosses the axis at $17^{\circ} 25^{\prime} \mathrm{S}$ (lines 1,2 and 3 in Fig. 1) and the other at $18^{\circ} 25^{\prime} \mathrm{S}$ (line 4 in Fig. 1). The large-scale ridge morphology in this region is remarkably linear in character, but small left-stepping discontinuities occasionally offset the ridge axis by a few $\mathrm{km}$. The survey lines cross the center of two distinct ridge segments separated by an intervening segment. Each segment has a unique morphological character. The northern area at $17^{\circ} 25^{\prime} \mathrm{S}$ has a domed and swollen shape with no axial graben, whereas the

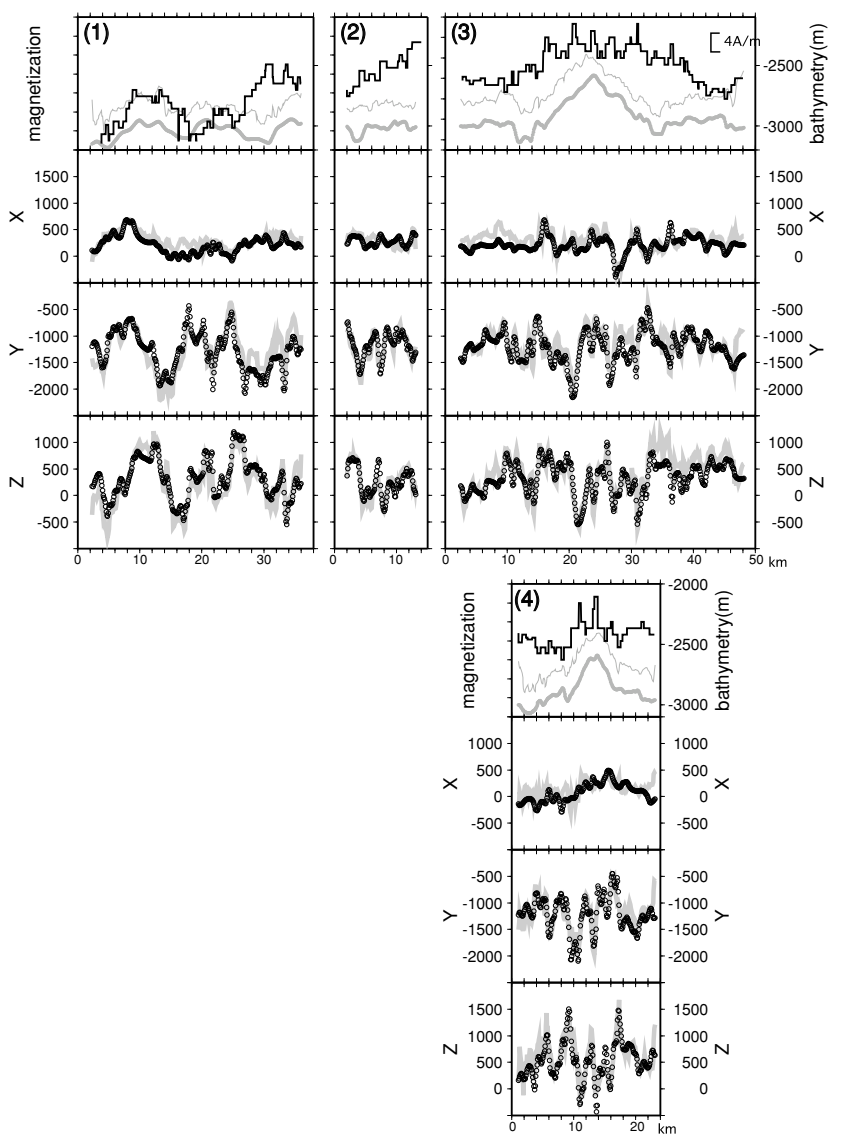

Fig. 2. Magnetization and forward model based on calculated magnetization intensity and magnetic boundaries. The results for each survey line are represented by a set of four boxes, arranged to keep the geometry between the survey lines on the geographical map (Fig. 1) as the boxes for lines 1, 2 and 3 are placed side by side and those for lines 3 and 4 align vertically with the ridge axis. The horizontal axes represent distance $(\mathrm{km})$ in a $2 \mathrm{~km}$ scale unit. (top of the four boxes) relative variations of magnetization (dark line) with left scale. The zero level is arbitrary for each survey line. Light lines represent the bathymetry profile and fish track (upper, lower, bottom). Comparison of forward model using inversion solutions (circle) and observed magnetic field (thick light line). $\mathrm{X}, \mathrm{Y}, \mathrm{Z}$ components represent along track and perpendicular to track directions, and vertical, respectively.

ridge at $18^{\circ} 25^{\prime} \mathrm{S}$ has a steep and narrow profile with a relatively wide and deep graben. Both segments culminate at the same depth of about $2600 \mathrm{~m}$. Some different characteristics of the faults along the two survey lines are also found in published side-scan sonar data (Cormier and Macdonald, 1994; Carbotte et al., 1997). The western flank of the northern area $\left(17^{\circ} 25^{\prime} \mathrm{S}\right)$ has a fault density about three times less than the western flank of the southern area $\left(18^{\circ} 25^{\prime} \mathrm{S}\right)$ and both the northern and southern survey areas show fewer faults on the eastern flank than on the western flank of the ridge axis.

We use the Genetic Algorithm (GA) inversion method with a 2.5-dimensional magnetic structure model to obtain magnetic intensity distribution, each magnetic boundary strike and position (Yamamoto and Seama, 2004). In the 2.5-dimensional model, magnetic boundaries represented by vertical planes have various strikes to better express the magnetic structure. The GA's parallelism prevents the solution from falling in a local optimum and effectively leads to 


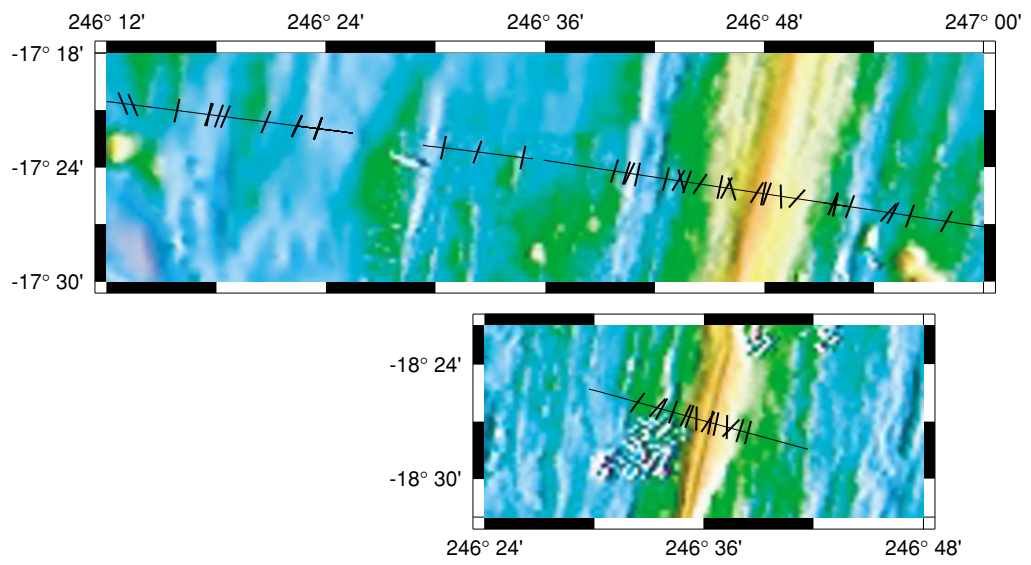

Fig. 3. Magnetic boundaries are superimposed on topography. Upper map shows the result along lines 1, 2 and 3. Lower map is for line 4. The boundaries with stronger magnetic contrast more than $2 \mathrm{~A} / \mathrm{m}$ were selected to plot on this map.

the best solution. Besides, calculation on the space domain saves the short wavelength in the observed data in order to take full advantage of near-bottom survey.

The given parameters are an azimuth of survey lines, magnetization vector direction, topography along the profile, and magnetic layer thickness. We assume that the magnetization direction is parallel to the geocentric axial dipole field and that the magnetic source is seismic layer 2A: the topography data, which are resampled along the each survey line at $100 \mathrm{~m}$ intervals from original [TAMU]2 sidescan sonar data, are used to define the top surface and are added with the thickness of layer $2 \mathrm{~A}$ to determine the bottom surface. This assumption is reasonable because extrusive basalt is the main source of marine magnetic anomalies at fast-spreading centers (Dyment and Arkani-hamed, 1995) and because deep-tow magnetic data are closer to and therefore have a stronger sensitivity to the uppermost layer of the oceanic crust, i.e. the volcanic basalt rocks on the surface of the oceanic crust. We use seismic data at the $17^{\circ}-17^{\circ} 40^{\prime} \mathrm{S}$ ridge area (Carbotte et al., 1997) to derive the thickness of layer $2 \mathrm{~A}$ for the north survey, line 3, while the south survey at $18^{\circ} 25^{\prime} \mathrm{S}$, line 4 , has had no seismic survey conducted nearby. Therefore, we used a synthetic thickness of the magnetic layer for line 4 . The thicknesses at the same distance from the ridge axis are collected and averaged from the nine profiles of seismic $2 \mathrm{~A}$ layer around $17^{\circ} 30^{\prime} \mathrm{S}$. The width of the thinning part at the ridge axis in the averaged layer is rescaled to the narrower width estimated from the width of the ridge dome at $18^{\circ} 25^{\prime} \mathrm{S}$. The thinnest point is set at the ridge axis and the whole thickness is shifted to make the layer at the axis $350 \mathrm{~m}$ thick, where the depth of AMC (Axial Magma Chamber) is observed below the ridge at $18^{\circ} 30^{\prime} \mathrm{S}$ by seismic data (Detrick et al., 1993). The final shape of the synthetic $2 \mathrm{~A}$ shows the change in thickness from $350 \mathrm{~m}$ at the axis to $580 \mathrm{~m}$ to side within lateral $4 \mathrm{~km}$. The reason to have the magnetic layer at $18^{\circ} 25^{\prime} \mathrm{S}$ imitating the one at $17^{\circ} 25^{\prime} \mathrm{S}$ rather than having a constant thickness is that previous studies reveal a similarity in velocity or thermal structure below the two ridges, which may imply similarity in the shape of magnetic source layer. For example, the AMC reflectors are detected at closer level (Detrick et al., 1993), the thickness of layer 2A is increasing with age in both area (Hooft et al., 1996, 1997), and both show strong hydrothermal discharges reflecting similar magmatic activity (Urabe et al., 1995; Auzende et al., 1996). On the other hand, the two off-ridge survey lines (lines 1 and 2) were assumed to have a constant thickness $(500 \mathrm{~m})$ magnetic layer.

\section{Paleomagnetic Intensity and Fine-scale Tecton- ics}

Results of each survey line are shown in Figs. 2 and 3. Given our data and assumptions, the resolution of computed parameters is $0.6 \mathrm{~A} / \mathrm{m}$ for magnetization intensity, $50 \mathrm{~m}$ for positions of the magnetic boundaries, and 2.5 degrees for their strikes. Forward modeled magnetic anomaly profiles computed using the final values of the searched parameters are in good agreement with the original observations.

The positions and directions of magnetic boundaries are superimposed on the topography in Fig. 3. The result indicates that the off-ridge magnetic boundaries are mostly parallel to the tectonic lineations. Two boundaries at the western edge of line 1 are located on and aligned with the outline of the V-shaped smooth seafloor created by the southward propagation ridge (Cormier et al., 1996). The rest of the off-ridge boundaries are parallel to the spreading ridge. On the other hand, the ridge-swelling areas of lines 3 and 4 exhibit various directions of boundaries and they seem to be related neither to the topographic lineations nor to the fault strikes. These boundaries probably reflect the outline of the lava flow in these areas. The rambling lava flow inferred from our result agrees with the observation that the lobate outlines of lava flow cross the topographic linear feature (Sinton et al., 2002) and also agrees with Shah et al. (2003) in which they showed the multidirectional magnetic field in this study area.

Magnetic intensity distribution along line 3 (Fig. 2) exhibits symmetric character in a long wavelength pattern. It presents a bell-like shape about $20 \mathrm{~km}$ off-axis to reach stable low value in side. This symmetric form shows the general tendency that the older crust has a lower magnetization, which is known as the result of the low-temperature alteration of extrusive basalts with time (Johnson and Tivey, 1995). However, the narrow youngest zone in a few $\mathrm{km}$ from the axis does not conform to this tendency, where the 


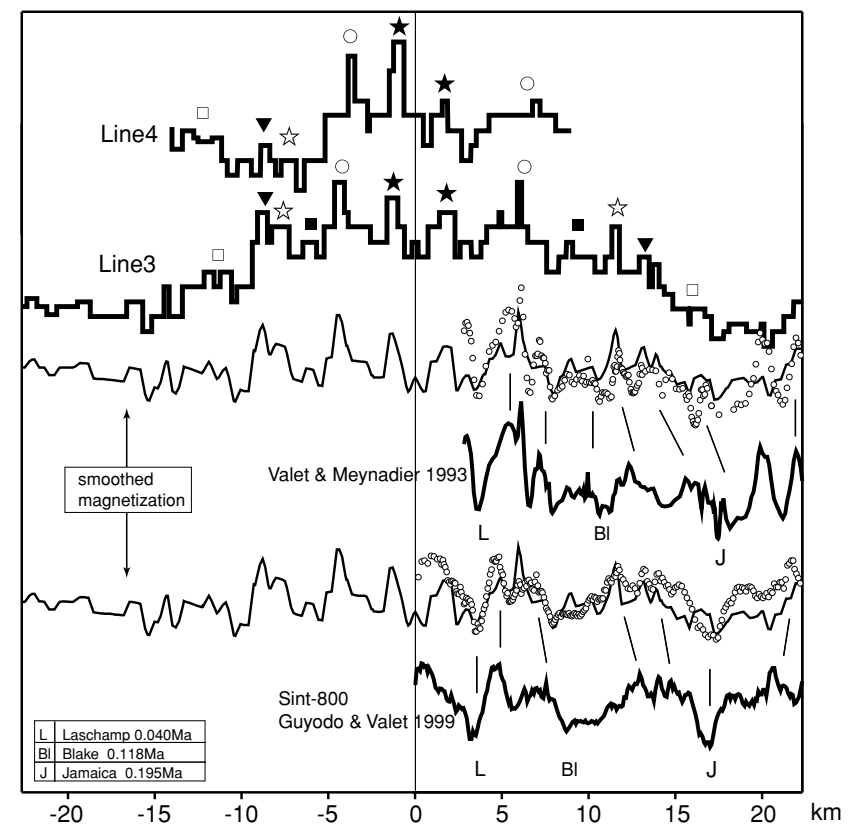

Fig. 4. (upper 2 rectangular line) Comparison of magnetization pattern between lines 3 and 4 across the ridge axis. Symbols mark peaks supposedly of the same age (lower 4 lines). Comparison between magnetization intensity and geomagnetic paleointensity. Thin lines represent the smoothed version of line 3 magnetization intensity (see text). Thick line profiles represent geomagnetic paleointensity variations (Valet and Meynadier, 1993; Sint-800, Guyodo and Valet, 1999). Open circles superimposed to the magnetization intensity also represent paleointensity variations adjusted under the assumption of a variable spreading rate. Vertical bars connect the same ages of the original (constant rate, thick) and ajusted (variable rate, circle) paleointensity curves. A clear correlation is observed between the observed magnetization intensity and the geomagnetic paleointensity time scale.

magnetization is lower than the outer-located older crust. Such "Axial Magnetization Low (AML)" has been reported in previous studies (Perram et al., 1990; Tivey, 1994; Shah et al., 2003). Shah et al. (2003) explored possibilities for the source of the AML in this area and concluded that the shallow dikes, still keeping higher temperature than Curie point, may form a low-magnetization region. Although the AML in our result is wider than the one in Shah et al. (2003), it could originate in a similar thermal effect and our result should be affected by a deeper and wider source because of the difference in the survey level that is $20 \mathrm{~m}$ for Shah et al. (2003) and $200 \mathrm{~m}$ for this study. One probability is that the axis in this area is so hot that the lower part of seismic 2A layer is still not cool enough to bear a magnetization. Therefore, the discrepancy from our model with the whole magnetized 2A layer would create an apparent AML, and higher magnetization could be expected for a real magnetized layer of such a young age.

Pulse-like peaks in line 3 shows a symmetric character centered at $1 \mathrm{~km}$ off the ridge topographic axis (Figs. 2 and 4). The peak-to-peak interval and the area under each peak west of the axis are smaller than on the east side. Furthermore, some peaks found on the eastern side of the ridge axis are not present on the western side or merged into a composite peak. The cause of the short-wavelength pattern in the magnetization at the mid-ocean ridge still remains to be proved. Various degrees of hydrothermal alteration, seafloor topography, shape of magnetic layer, variation of rock chemistry, and paleointensity variation have been proposed as a solution. In this study, comparing the locations of the faults and magnetization lows shows no one-to-one relation, implying the hydrothermal alteration by seawater penetrating faults that Tivey and Johnson (1987) proposed is not the source for this short-wavelength pattern in this study area. The influence to the magnetization from unrealistically modeled topography is not taken into account because we used observed data. The possibility that the variation in thickness of the magnetic layer mainly causes the short-wavelength signal might be low. As we suggest above, the whole magnetized 2A layer could be a wrong assumption only for the narrow axis region. However, the rest of the ridge area remains reliable in the assumption of observed $2 \mathrm{~A}$ as the magnetic source layer, suggesting the calculated magnetization mostly reflects the actual magnetization itself. Rock-chemical variation could be also denied because chemical uniformity was reported in this area (Bergmanis et al., 1999).

We use the deep-sea sediment-derived record of paleointensity variation to verify whether the observed deep-sea marine magnetic anomalies present a robust record of geomagnetic paleointensity. We adopt the paleointensity composite record Sint-800 of Guyodo and Valet (1999) and the original sedimentary record of Valet and Meynadier (1993) for comparison. By stacking available records, Sint-800 is an up-to-date composite paleointensity record which is becoming a standard geomagnetic paleointensity timescale; conversely Valet and Meynadier's (1993) data provide a long and continuous paleointensity record from sediment cores for ages older than $0.8 \mathrm{Ma}$, to be compared to our off-axis data. However, our data and the sediment-derived records have differences that make a direct comparison difficult. In order to compare, the long wavelength component originated from the low-temperature alteration of extrusive basalts should be removed from the magnetization intensity because that is absent from the geomagnetic paleointensity timescale. We removed such long wavelengths by filtering with a $20 \mathrm{~km}$-width cosine filter. Additionally, our method is based on a block model that forces the magnetization intensity to be expressed as a rectangular function, while paleointensity profiles are recorded as continuous curves, thus we smoothed the rectangulars with a $0.7 \mathrm{~km}$-width filter to make the graphs comparable. Figure 4 shows the comparison of our original and modified magnetization intensity data with paleointensity variations. There are good correlations of the peak pattern of both profiles. Comparison with Valet and Meynadier (1993) shows good agreement, especially for the period between present and about $7 \mathrm{ka}$ before the Jamaica excursion. A variable, a little faster spreading rate is observed for times older than the Blake excursion, presents more obvious correlation (Fig. 4). Comparison with Sint-800 also shows good agreement. The superimposition with a profile computed with a variable rate (circles in Fig. 4) even yields a better match.

A comparison between lines 3 and 4 also shows good agreement with several correlating peaks despite the different ridge morphologies (Fig. 4). This suggests that both magnetization records are sampling the same geomagnetic 
field signal and are therefore of paleomagnetic origin. The most different part between lines 3 and 4 is the low magnetization in line 4 between the second peak (marked by a circle) and the western end of the profile. The low magnetization in the long-wavelength component in the west of line 4 could be explained by the high degree of fracture and faults prevailing there. Twelve faults, both inward and outward facing, are concentrated between the points of 3 and 9 $\mathrm{km}$ in the horizontal scale of Fig. 2(4) (Cormier and Macdonald, 1994), implying an extensive fracturation. In the corresponding part of line 3, only half of that number of faults is observed, separated by larger intervals (Carbotte $e t$ al., 1997). The congested fracture area may play an important role in the decay of magnetization, not in the spot of the fault location but in the prevailing background, because the each location of the fault seems to be unrelated to each magnetic boundary or magnetization low.

As for older age in the far western area (Fig. 5), the magnetization intensity profile and geomagnetic paleointensity curve present a good correlation up to the Cobb Mountain excursion (1.19 Ma), even assuming a constant spreading rate of $56 \mathrm{~km} / \mathrm{Ma}$. Remarkable matches are found in a few $\mathrm{km}$ wavelength features between our magnetization intensity and those of both Valet and Meynadier (1993) and Guyodo and Valet (1999) Sint-800 paleointensity curves. For instance, the gradual decline from the Biwa III excursion to the Big Lost excursion, and the sudden surges at the Delta excursion and at the Brunhes/Matuyama boundary, and a buldge corresponding to the Jaramillo subchron (Fig. 5). Some adjustment of the spreading rate age by age would lead to a better agreement and may conversely let us know more precisely the spreading rate in the study area. In should be noted that the correlation of short wavelengths is not as good in this off-axis area. The reasons might be the assumption of a constant source thickness $(0.5 \mathrm{~km})$ or other effects like the tectonic and/or hydrothermal activity that may disturb the paleointensity records as the crust gets older and goes away from the ridge. More information about off-axis crustal structures from seismic and geochemical observation is needed to ascertain this point.

The crustal age inferred from the correlation of peaks on the eastern and western sides of the ridge axis suggests recent spreading rates of $88 \mathrm{~km} / \mathrm{Ma}$ to the east and $56 \mathrm{~km} / \mathrm{Ma}$ to the west (average for $0.28 \mathrm{Ma}$ ). This asymmetry of the spreading rate is large compared to the spreading rate of $76 \mathrm{~km} / \mathrm{Ma}$ to the east and $69 \mathrm{~km} / \mathrm{Ma}$ to the west that averaged over $5 \mathrm{Ma}$ and the large area $15^{\circ}-19^{\circ} \mathrm{S}$ (Lonsdale, 1989; Cormier et al., 1996). However, some sea-surface magnetic anomaly profiles near $17.5^{\circ} \mathrm{S}$ show the asymmetric spreading of 60 percent faster to the east in the Brunhes period (figure 15 in Lonsdale, 1989). This is the same balance in the eastward and westward spreading rates as our result shows, suggesting that the degree of the asymmetry becomes larger sometime before the Brunhes period and the maximum asymmetric ratio is afterward kept up to the present. Cormier et al. (1996) suggests that spreading asymmetry in this area can be entirely explained by the southward migration of overlapping spreading centers (OSCs) that is an effective way to transfer the lithosphere from the Pacific to the Nazca Plates. In other words, an

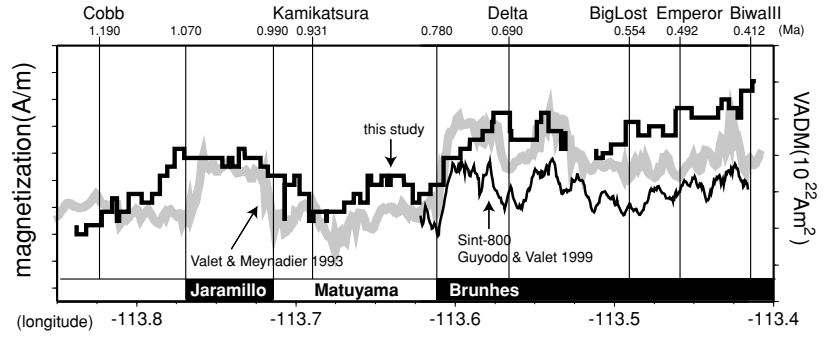

Fig. 5. Comparison of off-ridge profiles. Thick rectangular-like lines represent magnetization intensity of lines 1 and 2 . Thick gray line and thin black line are the relative paleointensity in virtual axial dipole moment (VADM) units, plotted assuming $56 \mathrm{~km} / \mathrm{Ma}$ spreading rate and setting $0 \mathrm{Ma}$ at the ridge axis. Names and ages of excursions are based on Valet and Meyradier (1993).

absence of OSCs would produce a symmetric spreading. However, the study area at $17^{\circ} 25^{\prime} \mathrm{S}$ is considered to drive the OSCs outward with its strong magmatic regime and no OSC existed since $1 \mathrm{Ma}$. Therefore, this large asymmetry within $0.28 \mathrm{Ma}$ cannot be explained by the OSC migration. An alternative explanation, for example, the continuous small ridge jumps to west, is needed.

In conclusions, our results assure that the magmatic oceanic crust indeed records paleomagnetic intensity variations, which are reflected by marine magnetic anomalies if observed at a sufficiently high resolution, i.e. close to the seafloor. Near-bottom vector magnetic surveys and the analysis method specially developed for such high-resolution data, together with a proper geomagnetic timescale, can play an essential role in understanding the detailed process of the mid-ocean ridge system.

Acknowledgments. We thank S. Carbotte, T. Sato, K. Tamaki, D. L. Carroll and, the WHOI Atlantis scientific party under the direction of T. Urabe. We also thank J. Dyment and T. Yamazaki for very carefully reviewing this manuscript and for their helpful suggestions. This experiment is part of the ridge flux program. This research was supported by Grant-In-Aid for Scientific Research (A)(2) (No. 14253003), the Japan Society for the Promotion of Science (JSPS), and by the Ministry of Education, Culture, Sports, Science \& Technology (MEXT), Japan through special coordination funds, 'Archaean Park Project' and 'the 21st Century COE Program of Origin and Evolution of Planetary Systems' (NS).

\section{References}

Auzende, J.-M., V. Ballu, R. Batiza, D. Bideau, J.-L. Charlou, M. H. Cormier, Y. Fouquet, P. Geistdoerfer, Y. Lagabrielle, J. Sinton, and P. Spadea, Recent tectonic, magmatic, and hydrothermal activity on the East Pacific Rise between $17^{\circ} \mathrm{S}$ and $19^{\circ} \mathrm{S}$ : Submersible observations, $J$. Geophys. Res., 101, 17995-18010, 1996.

Bergmanis, E., J. Sinton, S. White, K. C. Macdonald, R. Batiza, K. Rubin, T. K. P. Gregg, C. L. Van Dover, and K. Gronvold, Anatomy of a midocean ridge volcanic eruption: The Aldo-Kihi flow between $17^{\circ} 24^{\prime} \mathrm{S}$ and $17^{\circ} 34^{\prime}$ S, East Pacific Rise, Eos Trans. AGU, 80(46), Fall Meet. Suppl., F1075, 1999.

Bowers, N. E., S. C. Cande, J. S. Gee, J. A. Hildebrand, and R. L. Parker, Fluctuations of the paleomagnetic field during chron C5 as recorded in near-bottom marine magnetic anomaly data, J. Geophys. Res., 106, 26379-26396, 2001.

Bowles, J., L. Tauxe, J. Gee, D. McMillan, and S. Cande, Source of tiny wiggles in Chron C5: A comparison of sedimentary relative intensity and marine magnetic anomalies, Geochem. Geophys. Geosys., 4, 1049, doi:10.1029/2002GC000489, 2003.

Cande, S. C. and D. V. Kent, Ultrahigh resolution marine magnetic anomaly profiles: A record of continuous paleointensity variations?, $J$. 
Geophys. Res., 97, 15075-15083, 1992.

Carbotte, S. M., J. C. Mutter, and L. Xu, Contribution of volcanism and tectonism to axial and flank morphology of the southern East Pacific Rise, $17^{\circ} 10^{\prime}-17^{\circ} 40^{\prime} \mathrm{S}$, from a study of layer $2 \mathrm{~A}$ geometry, J. Geophys. Res., 102, 10165-10184, 1997.

Cormier, M.-H. and K. C. Macdonald, East Pacific Rise $18^{\circ}-19^{\circ}$ S: Asymmetric spreading and ridge reorientation by ultrafast migration of axial discontinuities, J. Geophys. Res., 99, 543-564, 1994.

Cormier, M. H., D. S. Scheirer, and K. C. Macdonald, Evolution of the East Pacific Rise at $16^{\circ}-19^{\circ} \mathrm{S}$ since $5 \mathrm{Ma}$ : Bisection of overlapping spreading centers by new, rapidly propagating ridge segments, Marine Geophys. Res., 18, 53-84, 1996.

Detrick, R. S., A. J. Harding, G. M. Kent, J. A. Orcutt, J. C. Mutter, and P. Buhl, Seismic Structure of the Southern East Pacific Rise, Science, 259, 499-503, 1993.

Dyment, J. and J. Arkani-hamed, Spreading-rate-dependent magnetization of the oceanic lithosphere inferred from the anomalous skewness of marine magnetic anomalies, Geophys. J. Int., 121, 789-804, 1995.

Fujiwara, T. and H. Fujimoto, Seafloor geomagnetic vector anomaly of the intersection of the Mid-Atlantic Ridge and the Kane Transform Fault: Implications for magnetization of the oceanic crust, J. Geophys. Res., 103, 30335-30349, 1998.

Gee, J., S. C. Cande, J. A. Hildebrand, K. Donnelly, and R. L. Parker, Geomagnetic intensity vatiation over the past $780 \mathrm{kyr}$ obtained from near-seafloor magnetic anomalies, Nature, 408, 827-832, 2000.

Guyodo, Y. and J. P. Valet, Relative variations in geomagnetic intensity from sedimentary records: the past 200,000 years, Earth Planet. Sci. Lett., 143, 23-36, 1996.

Guyodo, Y. and J. P. Valet, Global changes in intensity of the Earth's magnetic field during the past $800 \mathrm{kyr}$, Nature, 399, 249-252, 1999.

Guyodo, Y., C. Richter, and J. P. Valet, Paleointensity record from Pleistocene sediments (1.4-0 Ma) off the California Margin, J. Geophys. Res., 104, 22953-22964, 1999.

Hooft, E. E. E., H. Schouten, and R. S. Detrick, Constraining crustal emplacement processes from the variation in seismic layer 2A thickness at East Pacific Rise, Earth Planet. Sci. Lett., 142, 289-309, 1996.

Hooft, E. E. E., R. S. Detrick, and G. M. Kent, Seismic structure and indicators of magma budget along the southern East Pacific Rise, $J$. Geophys. Res., 102, 27319-27340, 1997.

Hussenoeder, S. A., M. A. Tivey, and H. Shouten, Direct inversion of potential fields from an uneven track with application to the Mid-Atlantic Ridge, Geophys. Res. Lett., 22, 3131-3134, 1995.

Hussenoeder, S. A., M. A. Tivey, H. Shouten, and R. C. Searle, Nearbottom magnetic survey of the Mid-Atlantic Ridge axis, $24^{\circ}-24^{\circ} 40^{\prime} \mathrm{N}$ : Implications for crustal accretion at slow spreading ridges, J. Geophys. Res., 101, 22051-22069, 1996.

Johnson, H. P. and M. A. Tivey, Magnetic properties of zero-age oceanic crust; a new submarine lava flow on the Juan de Fuca Ridge, Geophys. Res. Lett., 22, 175-178, 1995.

Lonsdale, P., Segmentation of the Pacific-Nazca spreading center, $1^{\circ} \mathrm{N}-$ 20 S, J. Geophys. Res., 94, 12197-12225, 1989.

Meynadier, L., J. P. Valet, R. Weeks, N. J. Shackleton, and V. L. Hagee, Relative geomagnetic intensity of the field during the last $140 \mathrm{ka}$, Earth Planet. Sci. Lett., 114, 39-57, 1992.

Mutter, J. C., S. M. Carbotte, W. Su, L. Xu, P. Buhl, R. S. Detrick, G. M. Kent, J. A. Orcutt, and A. J. Harding, Seismic Images of Active Magma Systems Beneath the East Pacific Rise Between $17^{\circ} 05^{\prime}$ and $17^{\circ} 35^{\prime} \mathrm{S}$, Science, 268, 391-395, 1995.

Perram, L. J., K. C. Macdonald, and S. P. Miller, Deep-tow magnetics near $20^{\circ}$ S on the East Pacific Rise: A study of short wavelength anomalies at a very fast spreading canter, Marine Geophys. Res., 12, 235-245, 1990. Pouliquen, G., Y. Gallet, P. Patriat, J. Dyment, and C. Tamura, A geomagnetic record over the last 3.5 million years from deep-tow magnetic anomaly profiles across the Central Indian Ridge, J. Geophys. Res., 106, 10941-10960, 2001.

Rea, D. K. and R. J. Blakely, Short-wavelength magnetic anomalies in a region of rapid seafloor spreading, Nature, 225, 126-128, 1975.

Scheirer, D. S. and K. C. Macdonald, Variation in cross-sectional area of the axial ridge along the East Pacific Rise: Evidence for the magmatic budget of a fast spreading center, J. Geophys. Res., 98, 7871-7886, 1993.

Scheirer, D. S., D. W. Forsyth, M.-H. Cormier, and K. C. Macdonald, Shipboard geophysical indications of asymmetry and melt production beneath the East Pacific Rise near the MELT Experiment, Science, 260, 1221-1224, 1998.

Shah, A. K., M.-H. Cormier, W. B. F. Ryan, W. Jin, J. Sinton, E. Bergmanis, J. Carlut, A. Bradley, and D. Yoerger, Episodic dike swarms inferred from near-bottom magnetic anomaly maps at the southern East Pacific Rise, J. Geophys. Res., 108, doi:10.1029/2001JB000564, 2003.

Sinton, J., E. Bergmanis, K. Rubin, R. Batiza, T. K. P. Gregg, K. Groenvold, K. C. Macdonald, and S. M. White, Volcanic eruptions on midocean ridge: New evidence from the superfast spreading East Pacific Rise, $17^{\circ}-19^{\circ}$ S, J. Geophys. Res., 107, 10.1029/2000JB000090, 2002.

Tivey, M. A., Fine-scale magnetic anomaly field over the southern Juan de Fuca Ridge: Axial magnetization low and implications for crustal structure, J. Geophys. Res., 99, 4833-4855, 1994.

Tivey, M. A. and H. P. Johnson, The central anomaly magnetic high: Implications for ocean construction and evolution, J. Geophys. Res., 92, 12685-12694, 1987.

Tivey, M. A. and H. P. Johnson, Variations in oceanic crustal structure and implications for the fine-scale magnetic anomaly signal, Geophys. Res. Lett., 20, 1879-1882, 1993.

Urabe, T., E. T. Baker, J. Ishibashi, R. A. Feely, K. Marumo, G. J. Massoth, A. Maruyama, K. Shitashima, K. Okamura, J. E. Lupton, A. Sonoda, T. Yamazaki, M. Aoki, J. Gendron, R. Greene, Y. Kaiho, K. Kisimoto, G. Lebon, T. Matsumoto, K. Nakamura, A. Nishizawa, O. Okano, G. Paradis, K. Roe, T. Shibata, D. Tennant, T. Vance, S. L. Walker, T. Yabuki, and N. Ytow, The Effect of Magmatic Activity on Hydrothermal Venting Along the Superfast-Spreading East Pacific Rise, Science, 269, 1092-1095, 1995.

Wooldridge, A. L., C. G. A. Harrison, M. A. Tivey, P. A. Rona, and H. Schouten, Magnetic modeling near selected areas of hydrothermal activity on the Mid-Atlantic and Gorda Ridges, J. Geophys. Res., 97, 10911-10926, 1992.

Valet, J. P. and L. Meynadier, Geomagnetic field intensity and reversals during the past four million years, Nature, 366, 234-238, 1993.

Valet, J. P., J. Brassart, X. Quidelleur, V. Soler, P. Y. Gillot, and L. Hongre, Paleointensity variations across the last geomagnetic reversal at $\mathrm{La}$ Palma, Canary Islands, Spain, J. Geophys. Res., 104, 7577-7598, 1999.

Yamamoto, M. and N. Seama, Genetic Algorithm inversion of geomagnetic vector data using a 2.5 dimensional magnetic structure model, Earth Planets Space, 56, 217-227, 2004.

Yamazaki, T., Relative paleointensity of the geomagnetic field during Brunhes Chron recorded in North Pacific deep-sea sediment cores: orbital influence?, Earth. Planet. Sci. Lett., 169, 23-35, 1999.

M. Yamamoto (e-mail: michiko@geology.geo.cornell.edu), N. Seama, and N. Isezaki 